discussions. The seven new projects are listed below:

- Criteria for assessment and quality assurance of material to be presented on the Internet under the auspices of IUPAC. CTC and the Committee on Printed and Electronic Publications (CPEP) are suggested coordinators. (Project proposal by Dr. Duffus)

- Exposure assessment. IUPAC minisymposium within the $9^{\text {th }}$ IUTOX Conference in Brisbane, 8-13 July 2001 (Coordinator: Dr. Duffus).

- Educational material for teaching chemistry related to case studies for risk assessment in toxicology. Senior high school level, in addition to the ongoing project "Toxicology: An Introduction" (Coordinator: Dr. Duffus; joint project with CTC).

- Modeling human exposure in the workplace (Coordinator: Dr. Erik Olsen).

- Exposure assessment for neurochemically active metals/manganese species (Coordinator: Dr. Jytte M. Christensen; participants: Prof. Douglas M. Templeton, Ingvar Thomassen, Dr. Erik Olsen, Harry Roels).

- Immunochemistry in metal exposure, possibly with a focus on nickel and beryllium (Coordinator: Prof.
Douglas M. Templeton; participants: Dr. Regine Heinrich-Ramm and Dr. Jytte Molin Christensen).

- Conference on risk assessment of particulate matter, with a focus on fibers. The proceedings will be published as a monograph (Coordinator: Prof. R. P. Nolan).

Dr. Duffus will continue as chairman, Prof. Douglas M. Templeton will become secretary, and Dr. Erik Olsen and Prof. Monica Nordberg are new Titular Members. Dr. Birger Heinzow became secretary of the Division. Prof. Dr. Laszlo Nagymajényi and Dr. Jytte Molin Christensen will be new Associate Members. New associate members will be contacted by the secretary, informed about ongoing activities, and invited to join existing projects and to generate and propose new projects.

The Commission met again 28 September-1 October 2000 in Szeged, Hungary.

\section{Birger Heinzow \\ Secretary, IUPAC Commission on Toxicology \\ VII.C.2}

\title{
Conference Announcements
}

designates IUPAC sponsorship.

\section{$6^{\text {th }}$ Rio Symposium on Atomic Spectrometry, 3-9 December 2000, Pucon, Chile}

Part I of this meeting will comprise a scientific program of plenary lectures, short oral presentations, and posters on atomic absorption, optical emission, atomic fluorescence, and inductively coupled plasma (ICP)mass spectrometry. Specific topics will include the following:

- instrumentation developments

- new method developments

- vapor generation techniques

- sample preparation and pretreatment

- preconcentration

- sample introduction

- solid and slurry sampling

- interferences, their mechanisms and their prevention

- flow injection and miniaturization

- elemental speciation analysis

- quality assurance

- chemometrics in atomic spectroscopy

- applications in environmental, industrial, clinical, toxicological, biochemical, food, drug, agricultural, hydrological, geological, mineralogical, metallurgical, and petrochemical samples; in process control and analysis; and in high-purity materials.

Part II of the symposium will consist of a workshop on fundamental studies and instrumental developments in electrothermal atomic absorption spectrometry, electrothermal vaporization, inductively coupled plasma, and optical emission and mass spectrometry, presented as research papers in invited lectures and short oral presentations.

For further information, contact the Coordinator, Prof. Dr. Carlos G. Bruhn, Departamento de Analisis Instrumental, Facultad de Farmacia, Universidad de Concepcion, P.O. Box 237, Concepcion, Chile; E-mail: cbruhn@udec.cl; Tel.: +56 41 204252; Fax: +56 41 231903; Web site: http://www.udec.cl/6riosymp/.

\section{$6^{\text {th }}$ International Conference on Solar Energy and Applied Photochemistry, 3-8 April 2001, Cairo, Egypt}

This conference and an associated workshop aim to provide a means of communication between scientists in different academic disciplines who share a common 